\title{
Screening the Antibacterial Activities of Streptomyces Extracts against Phytopathogens Xanthomonas oryzae pathovar oryzae, Xanthomonas campestris pathovar vesicatoria, and Pectobacterium carotovorum pathovar carotovorum
}

\author{
Seung-Hwan Kim · Jinhua Cheng - Seung Hwan Yang • Joo-Won Suh • \\ Eun-Sung Song $\cdot$ Lin-Woo Kang* (D) Jeong-Gu Kim* (D)
}

Received: 7 May 2015 / Accepted: 7 July 2015 / Published Online: 30 September 2015

(C) The Korean Society for Applied Biological Chemistry 2015

\begin{abstract}
Xanthomonas oryzae pv. oryzae (Xoo), X. campestris pv. vesicatoria $(X c v)$, and Pectobacterium carotovorum pv. carotovorum $(P c c)$ are the causative agents of bacterial blight in rice, bacterial spot in pepper, and bacterial soft rot in carrot and cabbage, respectively. To isolate novel microbial extracts with antimicrobial activities against these bacteria, approximately 5,300 different Streptomyces extracts were prepared and tested. Microbial cultures from various Streptomyces strains isolated from the Jeju Island, Baekam, Mankyoung river, Jiri mountain etc. in Korea were extracted into three different factions -secreted hydrophobic, secreted hydrophilic, and mycelia- using ethyl acetate, water, and methanol. Initially, 34, 29, and 10 extracts were selected as having antibacterial activities against $X o o, X c v$, and $P c c$, respectively. Extracts 1169G4, 1172E9, and 1172E10 had the
\end{abstract}

S.-H. Kim · E.-S. Song · J.-G. Kim

Genomics Division, National Academy of Agricultural Science (NAAS), Rural Development Administration (RDA), Jeonju 560-500, Republic of Korea

J. Cheng $\cdot$ J.-W. Suh

Division of Bioscience and Bioinformatics, College of Natural Science, Myongji University, Yongin 449-728, Republic of Korea

\section{S. H. Yang}

Interdisciplinary Program of Biomodulation, Myongji University, Yongin 449-728, Republic of Korea

\section{L.-W. Kang}

Department of Biological Sciences, Konkuk University, Hwayang dong, Gwangjin-gu, Seoul 143-701, Republic of Korea

*Corresponding authors (L.-W. Kang: lkang@konkuk.ac.kr; J.-G. Kim: jkim5aug@korea.kr)

This is an Open Access article distributed under the terms of the Creative Commons Attribution Non-Commercial License (http://creativecommons. org/licenses/by-nc/3.0/) which permits unrestricted non-commercial use, distribution, and reproduction in any medium, provided the original work is properly cited. highest growth inhibition activities against both Xoo and Xcv, and extracts $1151 \mathrm{H} 7$ and $1152 \mathrm{H} 7$ showed the highest growth inhibition activities against $P c c$.

Keywords antimicrobial activity $\cdot$ Pectobacterium carotovorum pathovar carotovorum - Streptomyces $\cdot$ Xanthomonas campestris pathovar vesicatoria $\cdot$ Xanthomonas oryzae pathovar oryzae

\section{Introduction}

Filamentous bacteria belonging to the genus Streptomyces produce over $50 \%$ of the antibiotics discovered to date (Taddei et al., 2006; Jayapal et al., 2007). Streptomyces bacteria and other Actinomycetes produce a diverse array of antibiotics, including aminoglycosides, anthracyclins, glycopeptides, $\beta$-lactams, macrolides, nucleosides, peptides, polyenes, polyethers, and tetracyclines (Mellouli et al., 2003).

Rice, pepper, and cabbage are the first, second, and third most cultivated crops, respectively, in Korea. Xanthomonas oryzae pv. oryzae $(X o o)$ and $X$. campestris pv. vesicatoria $(X c v)$ are the causal agents of bacterial blight in rice and bacterial spot in pepper, respectively (Yang et al., 2005; Adhikari et al., 2010). Pectobacterium carotovorum pv. carotovorum (Pcc) causes soft rot in a wide range of plants, including cabbage (Mole et al., 2010). Because these bacteria cause severe crop damage and reduce yield, prevention and treatment of these diseases have been the focus of intense research in both the academy and industry (Khush, 1997). In 2005, the whole genomes of Xoo and Xcv were sequenced (Frank Thieme, 2005; Lee et al., 2005). The emergence of resistance against $P c c$ was reported in 2007 (T. Luzzatto, 2007).

Chemical pesticides are routinely used to control plant pathogens in agricultural fields. However, recently, indiscriminate usage of 
chemical pesticides has raised many concerns, including environmental toxicity (Vivek K. Bajpai, 2010) and the possibility of generating antibiotic-resistant microbes. Therefore, biopesticides made from secondary metabolites from microbes or plants are being preferred over chemical pesticides.

The main objective of this study was to isolate novel antimicrobial Streptomyces extracts against the phytopathogens mentioned. Streptomyces species are ubiquitous in the soil, and play an important ecological role in the turnover of organic material. Furthermore, the diverse secondary metabolites produced by Streptomyces species are good sources of novel bioactive compounds. To date, more than half of the world's antibiotics (over 50 different antibiotics) have been isolated from Streptomyces. In this study, we prepared and screened 5,328 Streptomyces extracts, and tested their antimicrobial activities against $\mathrm{Xoo}, \mathrm{Xcv}$, and Pcc.

\section{Materials and Methods}

Strains and Culture Conditions. $X$. oryzae pv. oryzae KACC10331 (Xoo), X. campestris pv. vesicatoria KACC11127 (Xcv) and $P$. carotovorum pv. carotovorum KACC10227 (Pcc) were provided by the Korea Agriculture Culture Collection (KACC). Xoo, $\mathrm{Xcv}$, and $P c c$ were grown in YPD $(1.0 \%$ yeast extract, $2.0 \%$ peptone, and $2.0 \%$ dextrose) rich media at $28^{\circ} \mathrm{C}$. Streptomyces strains, collected from various regions of the Republic of Korea, including Jeju island, Baekam, Mankyoung river, Jiri mountain etc. (STable 1), were maintained at the Extract Collection of Useful Microorganisms library at the Myoungji University, and grown at $28^{\circ} \mathrm{C}$ on GSS medium (1.0\% soluble starch, $2.0 \%$ glucose, $0.1 \%$ beef extract, $0.4 \%$ yeast extract, $0.2 \% \mathrm{NaCl}, 0.025 \% \mathrm{~K}_{2} \mathrm{HPO}_{4}$, and $0.2 \% \mathrm{CaCO}_{3}$ at $\left.\mathrm{pH} 7.2\right)$, Bennett's medium (1.0\% glucose, $0.1 \%$ yeast extract, $0.2 \%$ bacto-peptone, and $0.1 \%$ beef extract), or DYC medium (2.5\% dextrin, $1.2 \%$ dry yeast, $2.0 \%$ corn starch liqueur, $0.1 \% \mathrm{NaBr}$, and $0.1 \% \mathrm{CoCl}_{2}$ at $\mathrm{pH} 7.0$ ).

Preparation of the Streptomyces extracts. For preparation of Streptomyces extracts library, one gram of soil were suspended in 10 milliliter of $0.85 \% \mathrm{NaCl}$ solution and serially diluted. The diluted soil suspension were spread on Humic acid- vitamin (HV) agar medium $\left(0.1 \%\right.$ humic acid, $0.05 \% \mathrm{Na}_{2} \mathrm{HPO}_{4}, 0.071 \% \mathrm{KCl}$, $0.005 \% \mathrm{MgSO}_{4} \cdot 7 \mathrm{H}_{2} \mathrm{O}, 0.001 \% \mathrm{FeSO}_{4} \cdot 7 \mathrm{H}_{2} \mathrm{O}, 0.002 \% \mathrm{CaCO}_{3}$, $0.2 \%$ B-Vitamin solution, $1.8 \%$ agar at $\mathrm{pH} 7.2$ ) and incubated at $28^{\circ} \mathrm{C}$ for 14 days. The colony with representative actinomycetes were selected and identified by $16 \mathrm{~S}$ rDNA sequence. Then Streptomyces strains were cultured in three different media: GSS medium for nutrient-rich condition, Bennett's medium for moderatenutrition condition, and DYC medium for nutrient-poor condition. Three extract fractions were prepared from each Streptomyces culture broth. $30 \mathrm{~mL}$ of the culture broth were centrifuged at $5,000 \times \mathrm{g}$ for $10 \mathrm{~min}$. Mycelia were collected as a pellet, and extracted with $3 \mathrm{~mL}$ of methanol. This fraction was called "mycelia isolated from supernatant (MIS)". After pelleting the mycelia, the supernatant was further extracted with $30 \mathrm{~mL}$ of ethyl acetate and dried. The resulting dried extract was dissolved in $3 \mathrm{~mL}$ of methanol. This was called the "secreted hydrophobic (SHB) fraction". The remaining ethyl acetate-insoluble fraction was called the "secreted hydrophilic (SHL) fraction". Thirty microliter of each fraction was distributed into 96-well plate and dried completely before further use. The dry weights were measured to enable accurate calculation of GI50 (dose required to cause $50 \%$ growth inhibition).

Naming the Streptomyces extracts. All extracts were represented as " $0000 \mathrm{X} 0$." The four digits, preceding the alphabet "X," refer to the plate number, which is named according to the region from where the sample was collected. The alphabet $\mathrm{X}$ refers the row in which the sample was present (numbered from top to bottom) and the last digit represents the column (numbered from left to right). For instance, sample $1172 \mathrm{H} 2$ is located in the second column from the left and at the bottom row of the 96-well plate numbered 1172. In addition, the last digit of the extract's name represents the extract-type: 2, 5, and 8 represent SHL; 3, 6, and 9 represent MIS; and 4,7 , and 10 represent SHB.

Antimicrobial activity test. The antimicrobial activities of the extracts were estimated by the growth inhibition test using a single dose in two steps. In the first round of screening, all the extracts were stored in columns $2-10$ of the $96-$ well plate. Columns 1,11 , and 12 contained the control (medium only), bacterial culture, and

Table 1 Antibacterial extracts screened in the first and second round against $X o o, X c v$, and $P c c$

\begin{tabular}{|c|c|c|c|c|}
\hline & & Xoo & $X c v$ & $P c c$ \\
\hline \multirow{3}{*}{$1^{\text {st }}$} & SHL & 1119D8, 1117E2 & 1128D2, 1128B5 1128B2 & $1158 \mathrm{H} 5,1158 \mathrm{G} 2$ \\
\hline & SHB & $\begin{array}{l}\text { 1176A4, 1175D7, 1175A4, 1173E4, } \\
\text { 1172E10, 1169H4, 1169G4, 1159B10, } \\
\text { 1149F4, 1139G10, 1136G7, 1124A7, } \\
\text { 1120F10, 1119F10, 1119C10, 1117E4 }\end{array}$ & $\begin{array}{l}\text { 1175A4, 1169G4, 1169E10, 1144H7, } \\
1144 \mathrm{~A} 7,1141 \mathrm{H} 7,1141 \mathrm{~A} 10,1133 \mathrm{H} 10 \\
1132 \mathrm{H} 7,1131 \mathrm{H} 4,1128 \mathrm{H} 4,1128 \mathrm{C} 4 \\
1128 \mathrm{~B} 4,1121 \mathrm{~F} 101120 \mathrm{~F} 10,1172 \mathrm{E} 10\end{array}$ & 1153E7, 1152H7, 1151H7, 1158G7 \\
\hline & MIS & $\begin{array}{l}\text { 1175A3, 1173E3, 1172E9, 1169G3, } \\
\text { 1164E6, 1161F3, 1161E3, 1160D3, } \\
\text { 1159B9, 1158A6, 1149F3, 1144B6, } \\
\text { 1135H3, 1120F9, 1119C6, 1117E3 }\end{array}$ & $\begin{array}{l}1172 \mathrm{E} 9,1152 \mathrm{H} 3,1144 \mathrm{~A} 6,1141 \mathrm{H} 6 \\
1132 \mathrm{H} 6,1131 \mathrm{H} 3,1128 \mathrm{H} 6,1128 \mathrm{D} 3 \\
1128 \mathrm{C} 6,1128 \mathrm{~A} 3\end{array}$ & 1158H6, 1158G6, 1157A6, 1155E9 \\
\hline \multirow{3}{*}{$2^{\text {nd }}$} & SHL & - & - & - \\
\hline & SHB & 1172E10, 1169G4 & 1172E10, 1169G4 & $1152 \mathrm{H} 7,1151 \mathrm{H} 7$ \\
\hline & MIS & 1172E9 & $1172 \mathrm{E} 9$ & - \\
\hline
\end{tabular}


bacterial culture with $6 \%$ dimethylsulfoxide (DMSO), respectively. The Streptomyces extracts were dissolved in $40 \mu \mathrm{L}$ of $50 \%$ DMSO, and further diluted in $100 \mu \mathrm{L}$ of YPD medium. Xoo, Xcv, and $P c c$ were grown to the early exponential growth stage (absorbance at $600 \mathrm{~nm}\left[\mathrm{~A}_{600}\right]=0.2$ ), and $160 \mu \mathrm{L}$ of each bacterial culture was dispensed into separate 96-well micro-plates (Nunce, US). Then, $40 \mu \mathrm{L}$ of previously diluted Streptomyces extract was added to each well. The cultures were grown at $28^{\circ} \mathrm{C}$ with continuous shaking at $700 \mathrm{rpm}$. The $\mathrm{A}_{600}$ values of the wells in the culture plates were measured every $4 \mathrm{~h}$ for $20 \mathrm{~h}$ using a multimode micro-plate reader (Infinite ${ }^{\circledR}$ M200 PRO, TECAN, Switzerland). To measure the antibacterial activity of each extract, we calculated the growth inhibition rate (GIR) at $20 \mathrm{~h}$ for $\mathrm{Xoo}$ and $\mathrm{Xcv}$ and at $12 \mathrm{~h}$ for Pcc using the following formula:

$$
G I R=(1[C B] /[A B]) \times 100
$$

where $A$ was the $\mathrm{A}_{600}$ value of the bacterial culture with $6 \%$ DMSO; $B=0.2$, which was the $\mathrm{A}_{600}$ value of the bacterial culture when the extract was added; and $C$ was the $\mathrm{A}_{600}$ value of the bacterial culture after treatment with the extract. For the second growth inhibition screen, the extracts selected from the first assay were tested three times using the same procedure.

The amount of growth inhibition induced by each extract was measured at five different dosages $\left(1,10^{-1}, 10^{-2}, 10^{-3}\right.$, and $10^{-4}$
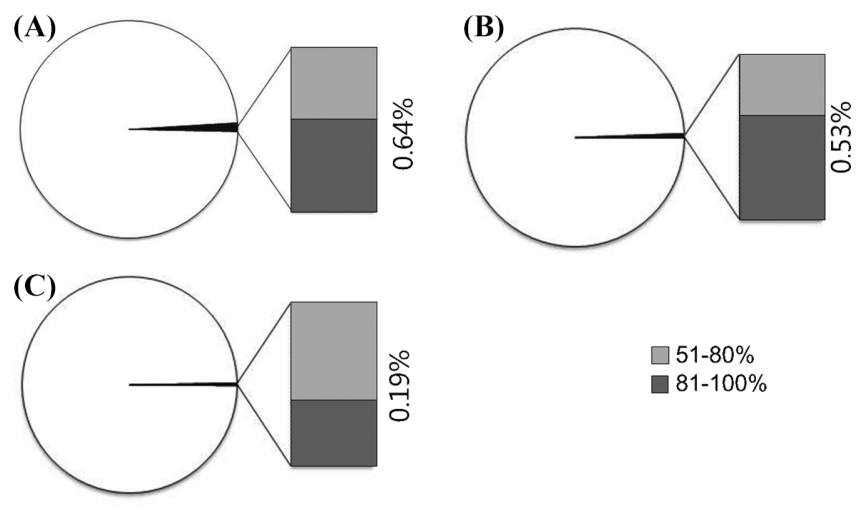

Fig. 1 A bar pie chart depicting the results of the first round of screening of the Streptomyces extracts for antimicrobial activity against (A) Xanthomonas oryzae pv. oryzae (Xoo), (B) X. campestris pv. vesicatoria $(X c v)$, and (C) Pectobacterium carotovorum pv. carotovorum (Pcc). The bar lists screened antimicrobial extracts that showed more than $50 \%$ growth inhibition. The percentages of screened extracts are indicated. Extracts showing growth inhibition of 51-80 and $81-100 \%$ are indicated separately in the enlarged bar. The Streptomyces extracts were prepared as described in the Materials and Methods.

dilutions) and compared with the controls. From this, the GI50 was calculated. All the tests were carried out in triplicate.
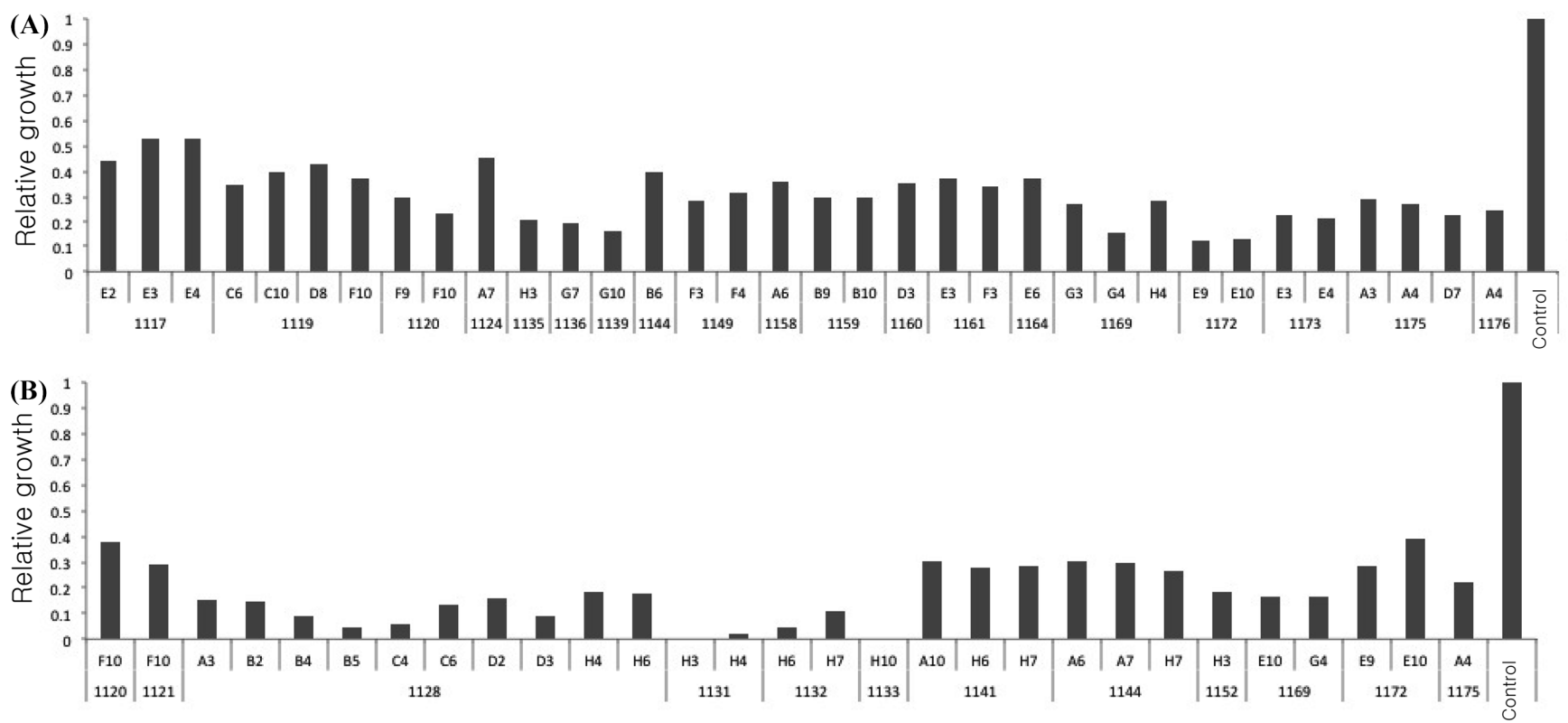

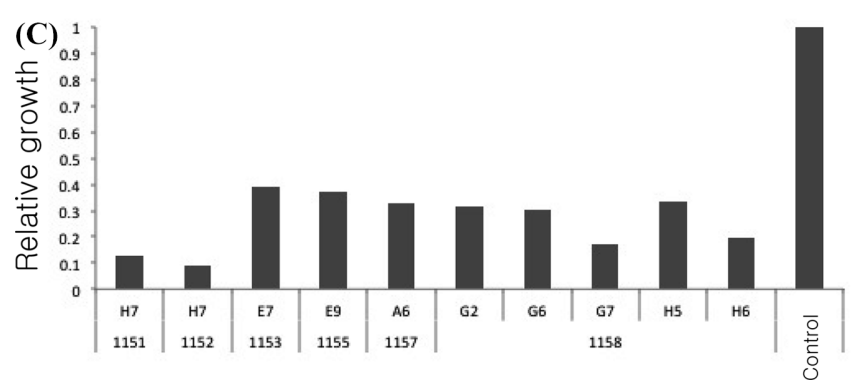

Fig. 2 First round of screening for antibacterial extracts against (A) Xoo, (B) $X c v$, and (C) $P c c$. The bar depicts the relative growth rate of (A) Xoo, (B) $X c v$, and (C) Pcc upon treatment with each screened extract, compared with the control (untreated bacterial culture). The relative growth for control was defined 1.0. Extracts are labeled as "0000X0," as described in the Materials and Methods. The first four numbers and the last two characters are labeled separately. 

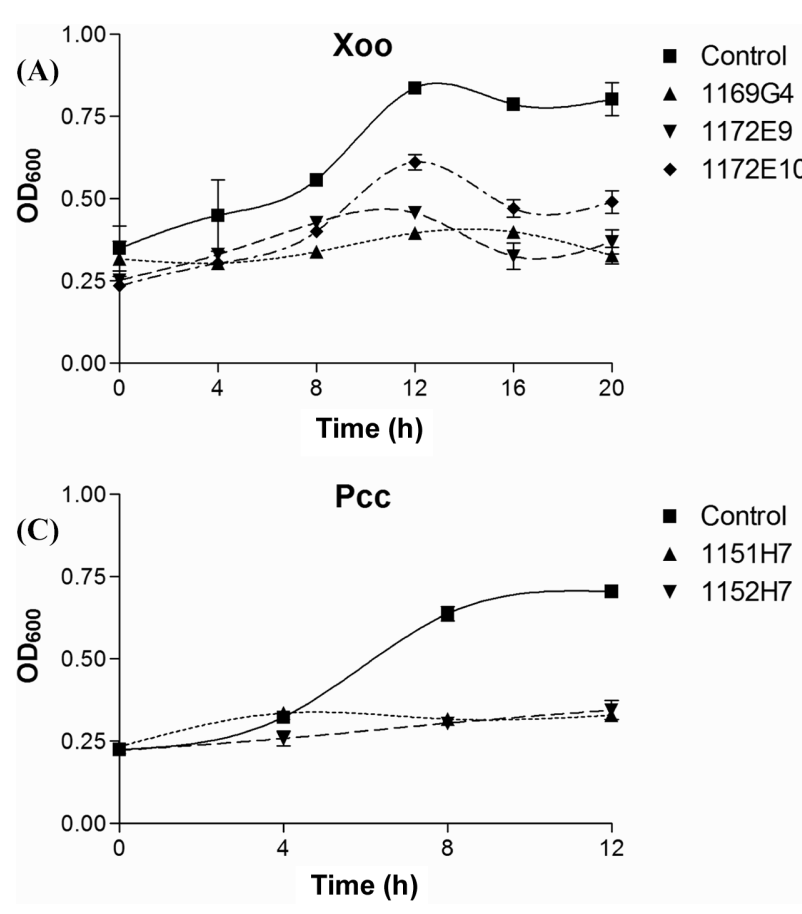

\section{Results}

Preparation of extracts from Streptomyces. Streptomyces strains produce diverse physiological secondary metabolites depending on the culture conditions. To generate various secondary metabolites from each Streptomyces strain, three culture media with different nutritional levels were used to grow the Streptomyces cells. In addition, three extract fractions were prepared for each Streptomyces culture. The MIS was separated from the supernatant; SHBs were extracted from the supernatant fraction using ethyl acetate; and SHLs were obtained from the residual water layer. In total, 5,328 extracts were prepared and screened for their antimicrobial activities against the three plant pathogens, $X o o, X c v$, and $P c c$.

First round of screening for antimicrobial activity. Extracts showing more than $50 \%$ cell growth inhibition activity were considered antimicrobial extracts; extracts 34, 29, and 10 were selected because they exhibited antimicrobial activity against $X o o$, $X c v$, and $P c c$, respectively. These three extracts constitute 0.64 , 0.53 , and $0.19 \%$ of all the extracts tested in the study (Fig. 1 and Table 1).

Extract 1172H9, the most effective antimicrobial extract against Xoo, inhibited $90 \%$ of Xoo cell growth. Of the top 34 extracts against Xoo, two were SHLs, 16 were MISs, and 16 were SHBs (Fig. 2A). Extract $1131 \mathrm{H} 3$ exhibited approximately $100 \%$ growthinhibition effect against $X c v$, and was the most effective antimicrobial against $X c v$. Of the top 29 extracts exhibiting growth-inhibition effect against $X c v$, three were SHLs, 10 were MISs, and 16 were SHBs (Fig. 2B). Extract $1152 \mathrm{H} 7$ showed $90 \%$ growth-inhibition activity against $P c c$, and was the most effective antimicrobial extract against $P c c$. Of the top 10 extracts showing growthinhibition effect against $P c c$, two were SHLs, four were MISs, and

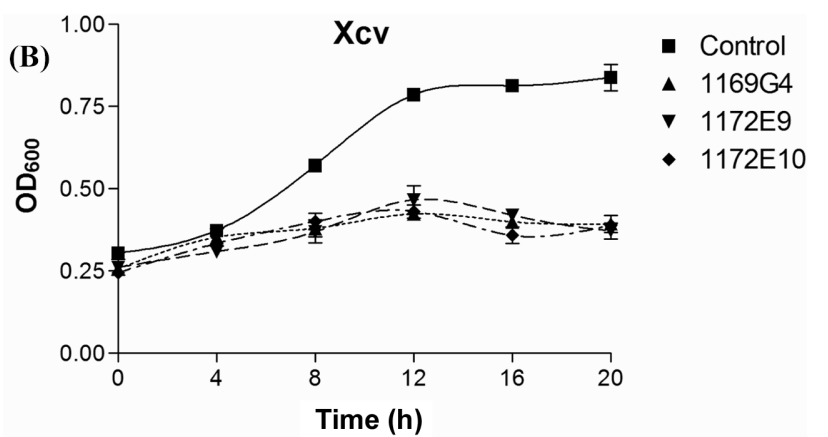

Fig. 3 The growth curve of (A) Xoo, (B) Xcv, and (C) Pcc upon treatment with the screened antibacterial extracts in the second round of growthinhibition screening. The extracts were added at the early exponential growth stage (absorbance at $600 \mathrm{~nm}\left[\mathrm{~A}_{600}\right]=0.2$, time $=0$ ) of each bacterial culture, and bacterial growth was monitored for an additional $12-15 \mathrm{~h}$ by measuring $\mathrm{A}_{600}$. Untreated bacterial culture was used as the control sample.

the remaining four were SHBs (Fig. 2C).

Second round of screening for antimicrobial activity. Extracts showing high growth-inhibition activity in the first round of screening were tested three times to confirm their antimicrobial activities. 1169G4 (SHB), 1172E9 (MIS), and 1172E10 (SHB) had the highest growth-inhibition activities against both Xoo and $X c v$ (Fig. 3A and 3B). 1172E9 (MIS) and 1172E10 (SHB) are from the same Streptomyces strain from Jeju island. 1169G4 (SHB) is also from Jeju island (S-Table 1). 1152H7 (SHB) and $1151 \mathrm{H} 7$ (SHB) showed the highest growth-inhibition activity against Pcc (Fig. 3C). 1152H7 (SHB) and 1151H7 (SHB) are from Baekam, Gyoungsangbukdo (S-Table 1). 1152H7 (SHB) showed slightly higher antibacterial activity than $1151 \mathrm{H} 7$ (SHB). In total, five different extracts -1169G4 (SHB), $1172 \mathrm{E} 9$ (MIS), 1172E10 (SHB), 1152H7 (SHB), and 1151H7 (SHB)- were found to possess antibacterial activities against Xoo, Xcv, and $P c c$. Interestingly, all the extracts, except 1172E9 (MIS), were SHBs.

The GI50s of the five antimicrobial extracts were measured by serial dilution of the extracts (Table 2). 1172E9 (MIS) and $1172 \mathrm{E} 10$ (SHB) showed the highest antibacterial activities against $X o o$ and $X c v$ (Fig. 4 and 5). In particular, 1172E10 (SHB) showed a GI50 value of less than $\mu \mathrm{g} \cdot \mathrm{mL}^{-1} .1152 \mathrm{H} 7$ (SHB) had a slightly

Table 2 Doses of screened antibacterial extracts required to cause $50 \%$ inhibition (GI50s) (Unit: $\mu \mathrm{g} \cdot \mathrm{mL}^{-1}$ )

\begin{tabular}{cccc}
\hline & Xoo & Xcv & Pcc \\
\hline $1169 \mathrm{G} 4$ & 4.1 & 1.7 & - \\
$1172 \mathrm{E} 9$ & $<1.7$ & $<1.7$ & - \\
$1172 \mathrm{E} 10$ & 0.3 & 0.4 & - \\
$1151 \mathrm{H} 7$ & - & - & 2.2 \\
$1152 \mathrm{H} 7$ & - & - & 0.5 \\
\hline
\end{tabular}



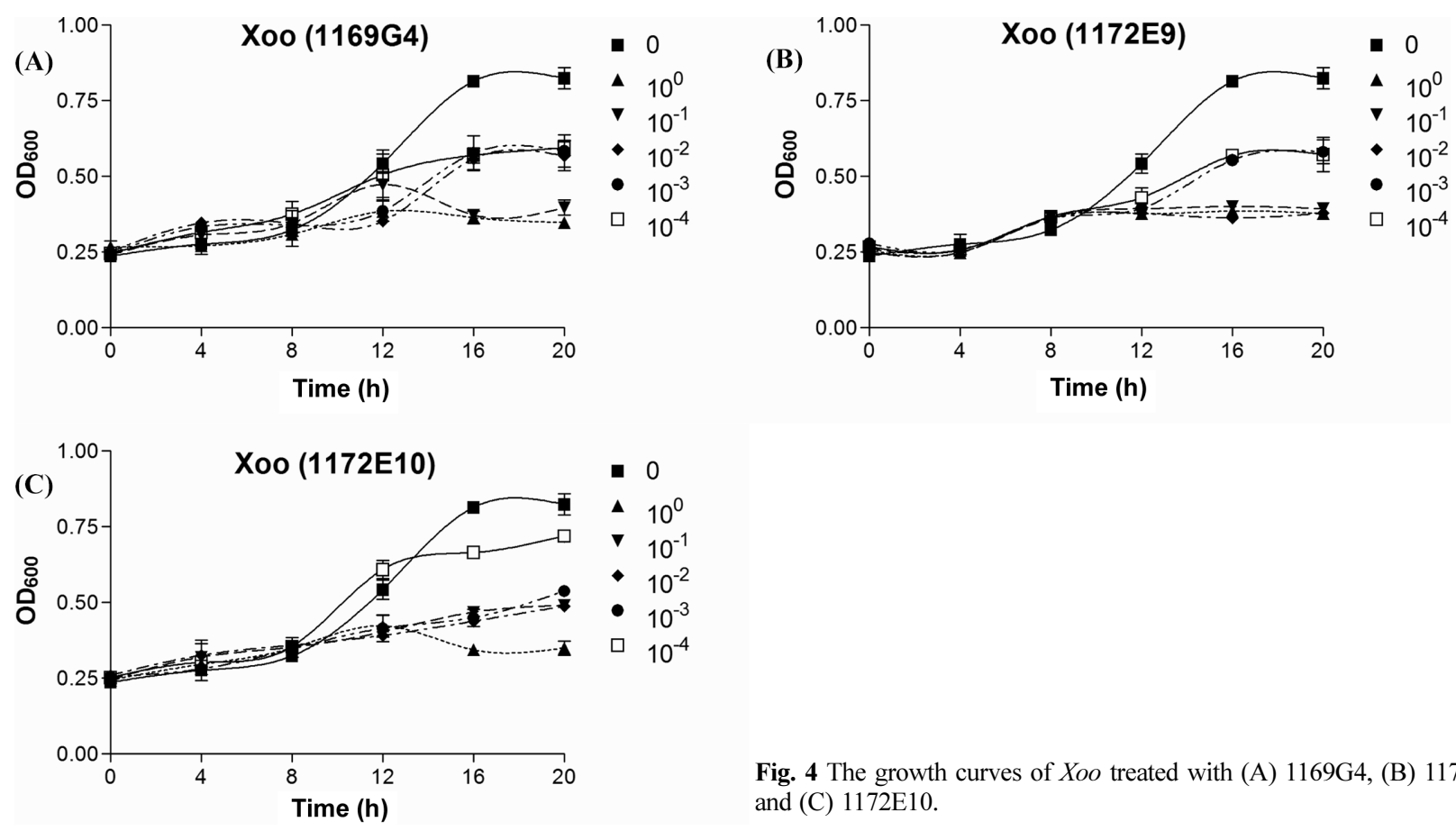

Fig. 4 The growth curves of Xoo treated with (A) 1169G4, (B) 1172E9, and (C) 1172E10.
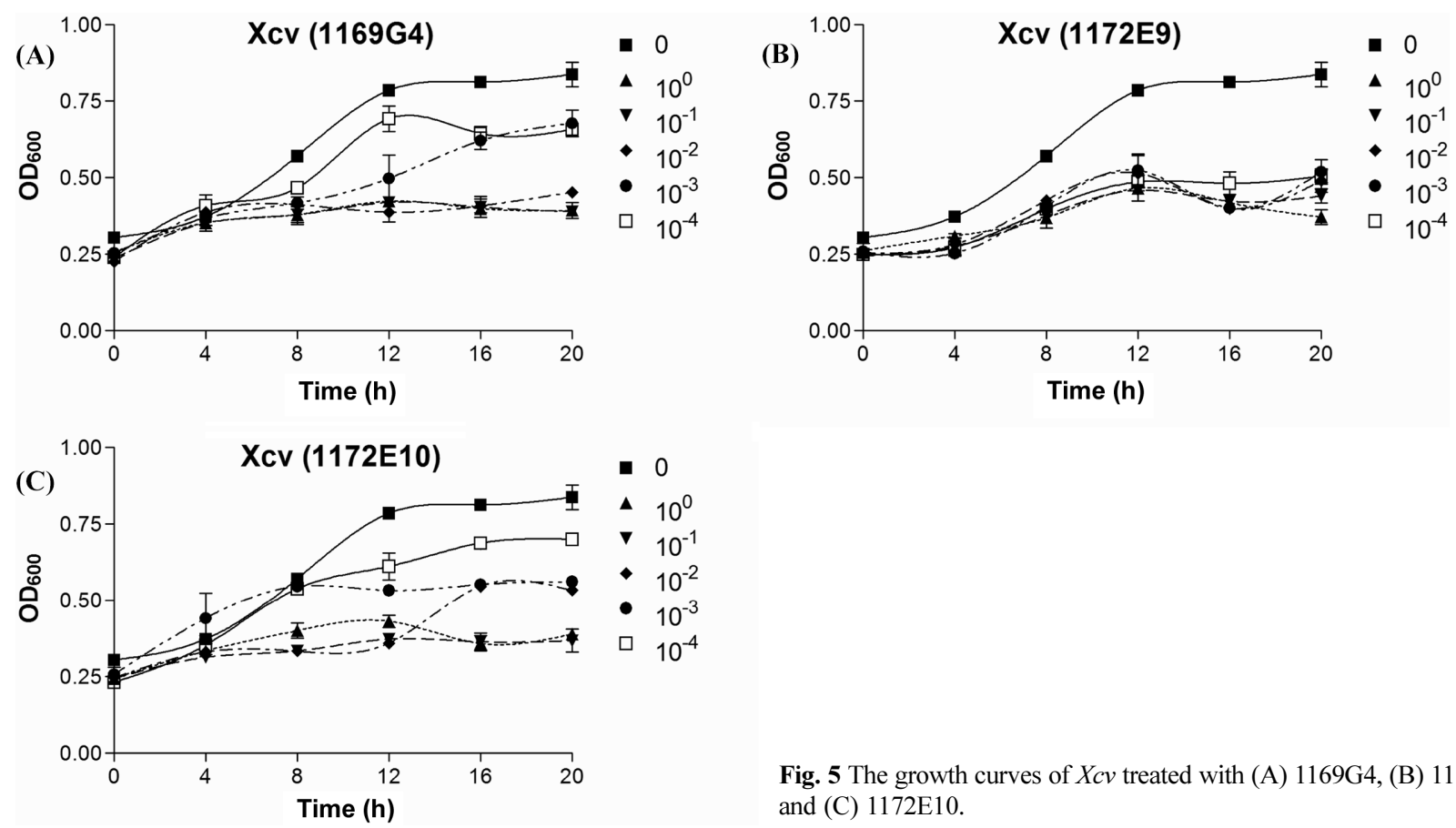

higher antibacterial activity than $1151 \mathrm{H} 7$ (SHB) against Pcc (Fig. 6). The antimicrobial activities of all five extracts were less than $\mu \mathrm{g} \cdot \mathrm{mL}^{-1}$. 1172E10 (SHB: MJM strain No. 10146GE) had the highest antimicrobial activity against $\mathrm{Xoo}$ and $\mathrm{Xcv}$ with GI50s of 0.3 and $0.4 \mu \mathrm{g} \cdot \mathrm{mL}^{-1}$, respectively. $1152 \mathrm{H} 7$ (SHB: MJM strain No. 9973DE) had the highest antimicrobial activity against $P c c$, with a GI50 of $0.5 \mu \mathrm{g} \cdot \mathrm{mL}^{-1}$.

Fig. 5 The growth curves of $X c v$ treated with (A) 1169G4, (B) 1172E9, and (C) 1172E10.

\section{Discussion}

Antibiotics are secondary metabolites that inhibit the growth of other microbial organisms. Growing incidences antibiotic-resistance among deadly pathogens has increased the need to discover novel antibiotics. Over the last few decades, new technologies for drug discovery have been developed, such as high throughput screening 

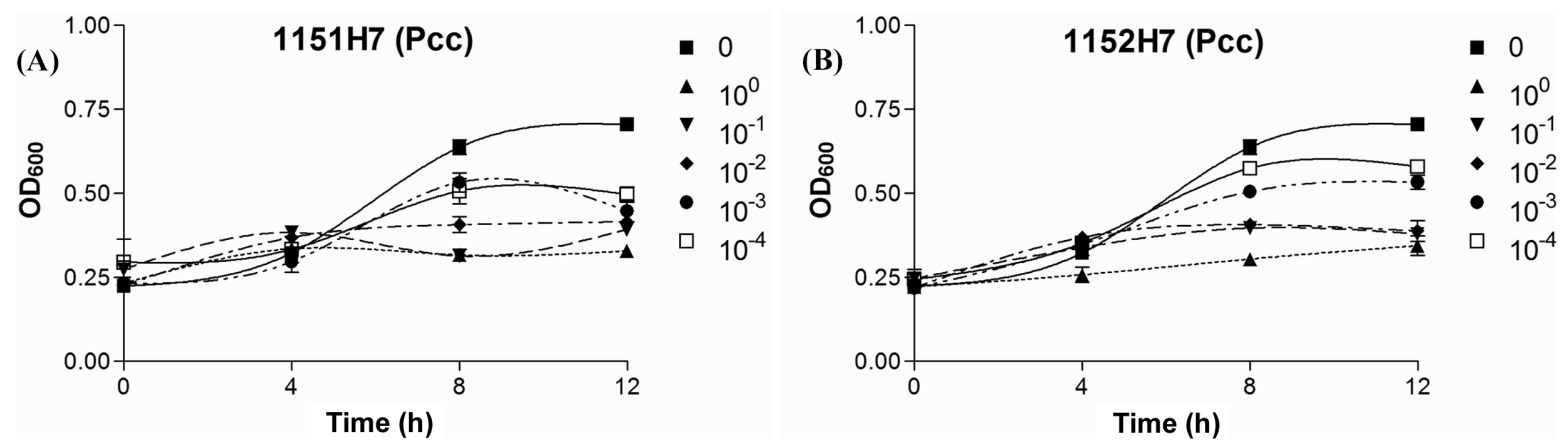

Fig. 6 The growth curves of $P c c$ treated with (A) $1151 \mathrm{H} 7$ and (B) $1152 \mathrm{H} 7$.

and combinatorial chemistry. Moreover, sequencing of pathogen genomes has led to the identification of new drug targets, and many chemical compounds have been synthesized by combinatorial chemistry and screened using cell-free assay systems and highthroughput screening systems. However, most screened compounds do not penetrate the pathogen to reach the target, or are easily degraded in vivo. Despite these technological advances, only five new classes of antibiotics have been introduced for human use (Talbot et al., 2006). Therefore, many studies are now focusing on screening secondary metabolites from microbes, especially Streptomyces, to identify novel antimicrobials. Streptomyces bacteria produce numerous secondary metabolites, and approximately $55 \%$ of currently used antibiotics are produced by the genus Streptomyces.

Five Streptomyces extracts showing high antimicrobial activity against $\mathrm{Xoo}, \mathrm{Xcv}$, and $\mathrm{Pcc}$ were screened. Of the five extracts, four $(1152 \mathrm{H} 7,1151 \mathrm{H} 7,1169 \mathrm{G} 4$, and 1172E10) were secreted and hydrophobic, and only one extract (1172E9) was non-secreted. The secretory and hydrophobic properties of the extracts aid in the penetration of bacterial cell walls (Nikaido H, 1976; Savage et al., 2002). In particular, 1169G4, 1172E9, and 1172E10 were effective against both $X c v$ and Xoo. The genus Xanthomonas belongs to Proteobacteria, and it causes a variety of diseases in numerous crops. The extracts identified in this study may have applications as a novel antimicrobial drug against Xanthomonas, including Xoo and $X c v$.

Acknowledgments This work was supported by grants from the RDA NextGeneration BioGreen 21 Program (No. PJ01132401).

\section{References}

Adhikari SR, Supakankunti S, and Khan MM (2010) Kala azar in Nepal: estimating the effects of socioeconomic factors on disease incidence. Kathmandu Univ Med J (KUMJ) 8, 73-9.

Frank Thieme RK, Thomas Bekel, Carolin Berger, Jens Boch, Daniela Büttner, Camila Caldana et al. (2005) Insights into Genome Plasticity and Pathogenicity of the Plant Pathogenic Bacterium Xanthomonas campestris pv. vesicatoria Revealed by the Complete Genome Sequence. Journal of Bacteriology 187, 7254-66.

Jayapal KP, Lian W, Glod F, Sherman DH, and Hu WS (2007) Comparative genomic hybridizations reveal absence of large Streptomyces coelicolor genomic islands in Streptomyces lividans. Bmc Genomics 8, 229

N. Huang, E. R. Angeles, J. Domingo, G. Magpantay, S. Singh, G. Zhang et al. (1997) Pyramiding of bacterial blight resistance genes in rice: markerassisted selection using RFLP and PCR. TAG Theoretical and Applied Genetics 95, 313-20.

Lee BM, Park YJ, Park DS, Kang HW, Kim JG, Song ES et al. (2005) The genome sequence of Xanthomonas oryzae pathovar oryzae KACC10331, the bacterial blight pathogen of rice. Nucleic Acids Res 33, 577-86.

Mellouli L, Ben Ameur-Mehdi R, Sioud S, Salem M, and Bejar S (2003) Isolation, purification and partial characterization of antibacterial activities produced by a newly isolated Streptomyces sp US24 strain. Research in Microbiology 154, 345-52.

Mole B, Habibi S, Dangl JL, and Grant SR (2010) Gluconate metabolism is required for virulence of the soft-rot pathogen Pectobacterium carotovorum. Mol Plant Microbe Interact 23, 1335-44.

Nikaido H (1976) Outer membrane of Salmonella typhimurium. Transmembrane diffusion of some hydrophobic substances. Biochimica et Biophysica Acta 433, 118-32.

Savage PB, Li C, Taotafa U, Ding B, and Guan Q (2002) Antibacterial properties of cationic steroid antibiotics. FEMS Microbiol Lett 217, 1-7.

T. Luzzatto MY Yishay, A. Lipsky, A. Ion, E. Belausov, and I. Yedidia (2007) Efficient, long-lasting resistance against the soft rot bacterium Pectobacterium carotovorum in calla lily provided by the plant activator methyl jasmonate. Plant Phathology 56, 692-701.

Taddei A, Rodriguez MJ, Marquez-Vilchez E, and Castelli C (2006) Isolation and identification of Streptomyces spp. from Venezuelan soils: Morphological and biochemical studies. I. Microbiological Research 161, 222-31.

Talbot GH, Bradley J, Edwards JE, Jr., Gilbert D, Scheld M, and Bartlett JG (2006) Bad bugs need drugs: an update on the development pipeline from the Antimicrobial Availability Task Force of the Infectious Diseases Society of America. Clin Infect Dis 42, 657-68.

Vivek K. Bajpai NTD, Hwa-Jin Suh, and Sun Chul Kang (2010) Antibacterial Activity of Essential Oil and Extracts of Cleistocalyx operculatus Buds Against the Bacteria of Xanthomonas spp. Journal of the American Oil Chemists' Society 87, 1341-9.

Yang W, Sacks EJ, Lewis Ivey ML, Miller SA, and Francis DM (2005) Resistance in Lycopersicon esculentum Intraspecific Crosses to Race T1 Strains of Xanthomonas campestris pv. vesicatoria Causing Bacterial Spot of Tomato. Phytopathology 95, 519-27. 